\section{PENGARUH SWEDISH MASSAGE TERHADAP PENURUNAN NYERI KEPALA KARENA MIGRAIN PADA LANSIA}

\author{
The Effect of Swedish Massage on The Reduction of Head Pain Due to Migraine \\ in The Elderly
}

\section{Raditya Kurniawan Djoar ${ }^{1}$, Anastasia Putu Martha Anggarani²}

\author{
1. Program Studi Keperawatan STIKES Katolik St. Vincentius a Paulo \\ 2. Program Studi Fisioterapi STIKES Katolik St. Vincentius a Paulo
}

\section{Riwayat artikel \\ Diajukan: 22 September \\ 2020 \\ Diterima: 25 September \\ 2020}

Penulis Korespondensi:

- Raditya Kurniawan Djoar

- Program Studi

Keperawatan STIKES

Katolik St. Vincentius a

Paulo

radit.stikvinct@gmail.c om

\section{Kata Kunci:}

Massage, nyeri kepala, lansia
Pendahuluan: Nyeri kepala adalah laporan rasa tidak nyaman atau nyeri dari seseorang dimana area nyeri melingkupi daerah kepala dari belakang kepala sampai ke dagu. Pada lansia prevalensi nyeri kepala sebesar 3,7-5,8\%. Kejadian nyeri kepala ini telah menjadi pusat perhatian peneliti karena merupakan jenis gejala yang paling banyak dijumpai yang berakibat menjadi keterbatasan dalam melakukan pekerjaan seharihari. Tujuan: Tujuan penelitian ini adalah menganalisis pengaruh swedish massage terhadap penurunan nilai nyeri kepala karena migraine pada lansia. Metode: Penelitian ini adalah penelitian perlakuan dengan pendekatan quasi eksperimental, dengan desain penelitian pre and post test two groups design. Populasi penelitian ini adalah lansia sebanayak 56 dimana sampel diambil dengan cara purposive sampling. Instrumen penelitian ini adalah VAS untuk mengevaluasi nyeri yang dirasakan lansia. Data dianalisis menggunakan program SPSS dengan menggunakan uji komparatif tidak berpasangan untuk data numerik (uji t tidak berpasangan/ Mann whitney). Hasil: Hasil uji statistik menunjukkan nilai signifikan 0.000 yang berarti ada pengaruh Swedish massage terhadap penurunan nilai nyeri migraine pada lansia. Kesimpulan: Tindakan massage memberikan efek pada system syaraf parasimpatis yang memungkin terjadinya relaksasi. Kondisi relaksasi memungkinkan sirkulasi darah menjadi lancar dalam pengiriman oksigen dan produk metabolisme yang ke system syaraf pusat. Gerakan efflurage pada Swedish massage memberikan pengaruh pada peningkatan aliran darah vena yang dapat menurunkan tekanan vena dan meningkatkan sirkulasi arteri. Gerakan kneading memberikan bantuan dalm aliran balik vena, sedangkan tindakan kompresi dapat meningkat sirkulasi pembuluh darah lokal dan tepi. Kondisi inilah yang memungkinkan terjadinya penurunan nyeri kepala atau migraine pada lansia.

\section{Abstract}

Background: Headache is pain or discomfort in the entire head area with the lower border from the chin to the back of the head. In the elderly, the prevalence of headache is 3.7-5.8\%. The incidence of headache has become the center of attention of researchers because it is the most common type of symptom that results in limitations in doing daily work. Objective: The purpose of this study was to analyze the effect of Swedish massage on reducing the value of migraine headaches in the elderly. Method: This type of research is an experiment with a quasi-experimental approach, with a pre and posttest two groups design. The population of this study was 56 elderly people where the sample was taken by purposive sampling. The research instrument was the VAS to evaluate the pain felt by the elderly. Data were analyzed using the SPSS program using the unpaired comparative test for numerical data (unpaired t test / Mann Whitney) The statistical test results showed a significant value of 0.000, which means there is an effect of Swedish massage on reducing the value of migraine pain in the elderly. Results: Result of the study showed that the majority of caregivers aged 26-45 years (adults) were The massage action has an effect on the parasympathetic nervous system which allows relaxation. Conclusion: The massage action has an effect on the parasympathetic nervous system which allows relaxation. Relaxation conditions allow blood circulation to be smooth in the delivery of oxygen and metabolic products to the central nervous system. The effleurages movement 
in Swedish massage has an effect on increasing venous blood flow which can lower venous pressure and improve arterial circulation. Kneading movements provide assistance in venous return, while compression may increase local and peripheral vascular circulation. This condition makes it possible to reduce headaches or migraines in the elderly.

\section{PENDAHULUAN}

Nyeri kepala adalah laporan rasa tidak nyaman atau nyeri dari seseorang dimana area nyeri melingkupi daerah kepala dari belakang kepala sampai ke dagu (Davis, 2006). Dimana kondisi tersebut sangat umum dijumpai dalam kehidupan sehari-hari. Kondisi ini bisa terjadi sebagai hasil perangsangan terhadap bagian tubuh di wilayah kepala dan leher yang peka terhadap nyeri. Faktor fisik dan psikis menjadi pemicu yang dominan dalam timbulnya nyeri kepala (Cady, 2007). Berdasarkan pengelompokan jenis nyeri kepala, nyeri kepala migren dan nyeri kepala tegang otot (tension headache) merupakan jenis nyeri kepala yang paling sering ditemukan di masyarakat (Goadsby, 2002). Situasi ini dapat mengganggu aktivitas sehari-hari karena nyeri kepala tegang otot biasa berlangsung dapat berlangsung dengan durasi 30 menit hingga 1 minggu penuh, nyeri bisa dirasakan kadang - kadang atau terus menerus (Boru, 2005). Masalah lain yang dapat timbul akibat nyeri kepala seperti gangguan tidur dengan gejala sering terbangun atau bangun dini hari, nafas pendek, susah buang air besar, penurunan berat badan, berdebar-debar dan gangguan haid (Davis, 2006).

Nyeri kepala banyak terjadi pada lansia dengan tingkat prevalensi pada populasi umum $3,7-5,8 \%$ (Davis, 2006). Kejadian nyeri kepala ini telah menjadi pusat perhatian peneliti karena merupakan jenis gejala yang paling banyak dijumpai yang berakibat menjadi keterbatasan dalam melakukan pekerjaan sehari-hari (Effendy, 2009). Observasi yang dilakukan di posyandu lansia Pelangi Nusantara mengambarkan sebanyak 65\% lansia mengeluh nyeri kepala. Tindakan yang dilakukan adalah tidur atau minum obat tanpa resep dokter. Hasilnya, 75\% lansia masih mengeluh nyeri yang mengganggu aktivitasnya. Oleh karena itu peneliti akan menganalisis pengaruh massage terhadap penurunan nilai nyeri kepala karena migraine pada lansia.

\section{METODE}

Jenis penelitian ini adalah penelitian perlakuan dengan pendekatan quasi eksperimental, dengan desain penelitian pre and post test two groups design. Populasi penelitian ini adalah lansia yang berada di panti werdha St Yosef dan lansia anggota kelompok pelangi nusantara kelurahan Darmo, Kecamatan Wonokromo Surabaya. Teknik Purposive sampling dilakukan untuk menentukan respoden penelitian dan didapatkan Besar sampel penelitian ini 56 orang lansia dengan kriteria lansia yang memiliki keluhan nyeri kepala migraine, Bersedia menjadi subyek penelitian dengan tuntas dari awal hingga akhir penelitian, Tidak sedang mengonsumsi obat pengurang nyeri pada saat penelitian berlangsung. Pemeriksaan derajat nyeri dengan menggunakan VAS dijelaskan pada klien secara verbal. Prosedur pengukuran nyeri ini yaitu pasien diminta untuk membuat garis vertikal yang melewati garis horizontal pada alat ukur. Alat ukur ini valid untuk mengevaluasi rasa nyeri. Pengukuran nyeri dilakukan sebelum dan sesudah diberikan tindakan Swedish massage. Data yang terkumpul ditabulasi dan dianalisis dengan menggunakan statistic dengan bantuan program SPSS. Untuk melihat pengaruh Swedish massage terhadap nyeri kepala karena migraine pada lansia, dilakukan uji komparatif tidak berpasangan (Uji t).

\section{HASIL DAN PEMBAHASAN HASIL PENELITIAN}

Pada bagian ini menunjukkan karakteristik umum dari responden dimana semua responden berjenis kelamin wanita. Sedangkan bila ditinjau dari kelompok umur berdasarkan kriteria dari departemen kesehatan tahun 2013, sebagian besar yang terlibat dalam proses penelitian ini berusia diatas 60 tahun.

\begin{tabular}{lccl}
\multicolumn{4}{c}{ Tabel 1 } \\
\hline No & Karakteristik & Jumlah & Prosentase \\
\hline 1 & Usia Lansia: & & \\
& $-\quad$ & Pra lansia \\
& (45-59 & & 26,7 \\
& tahun) & &
\end{tabular}




\begin{tabular}{ccc}
$\quad \begin{array}{l}\text { Lansia } \geq \\
60 \text { tahun }\end{array}$ & 41 & 73,3 \\
& & \\
Jenis Kelamin & & \\
Perempuan & 56 & $100 \%$ \\
Laki-laki & 0 & \\
\hline
\end{tabular}

Sunber: Data Primer

Pada tabel 2 menunjukkan bahwa ada selisih mean nilai nyeri sebelum dan sesudah pemberian intervensi Swedish massage pada lansia yang mengalami nyeri kepala karena migraine.

\section{Tabel 2 Nilai Nyeri}

\begin{tabular}{lll}
\hline No & Karakteristik & Mean \\
\hline 1 & Nilai nyeri Pre intervensi & $\begin{array}{l}3,20 \text { (Nyeri } \\
\text { sedang) }\end{array}$ \\
2 & Nilai Nyeri Post Intervensi & $\begin{array}{l}1,45 \text { (Nyeri } \\
\text { ringan) }\end{array}$ \\
\hline
\end{tabular}

Sumber: data Primer

Tabel 3 menunjukkan pemberian tidakan Swedish massage memberikan pengaruh yang significant dalam perubahan nilai nyeri kepala karena migraine pada lansia.

Tabel 3 Hasil Uji statistic

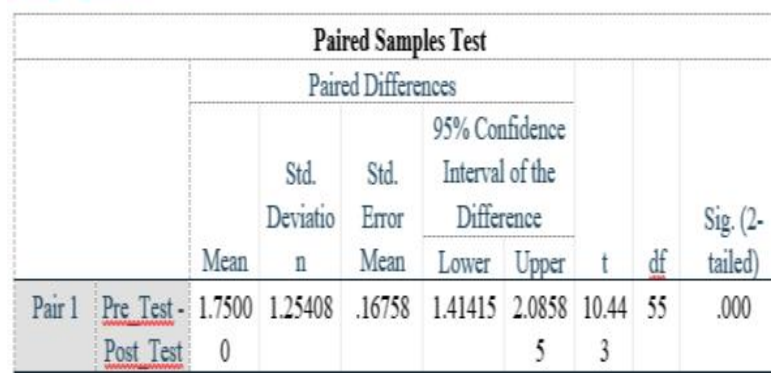

\section{PEMBAHASAN}

Bila ditinjau dari karakteristik responden menunjukkan bahwa sebagian besar responden $(73,3 \%)$ respoden sudah berusia lebih dari sama dengan 60 tahun, dan semua respoden berjenis kelamin perempuan. Mean nilai nyeri karena migran sebelum intervensi berada pada rentang nyeri sedang. Hal ini sesuai dengan teori sebelumnya bahwa faktor yang mempengaruhi kejadian migraine adalah jenis kelamin perempuan dan fluktuasi hormon karena penambahan usia. Kejadian migraine lebih sering terjadi 2-3 kali lipat pada perempuan (Susanti, 2020), selain itu angka kejadian migraine pada lansia mencapai 5,8\% (Davis, 2006). Perubahan hormon seks pada setiap individu memegang peranan yang signifikan terhadap kejadian migraine. Perubahan hormon disini termasuk juaga Fluktuasi hormon seks pada saat fase menapouse. Hormon perempuan esterogen mengalami fluktuasi selama daur kehidupan, hormon esterogen ini berperan dalam aktivasi serotonin. Pada wanita yang lansia hormon esterogen dalam tubuh menurun sehingga tubuh tidak mampu mengaktivasi serotonin. Kadar serotonin dalam tubuh yang rendah menyebabkan dilatasi pembuluh darah yang berlebihan di sistem saraf pusat. Dilatasi pembuluh darah berlebihan ini yang menyebabkan system syaraf pusat kekurangan oksigen yang memicu timbulnya nyeri kepala atau migraine. Selain itu, pada lansia juga sering mengalami kekakuan otot yang juga bisa menimbulkan gangguan sirkulasi darah pada system syaraf pusat yang juga dapat menyebabkan terjadinya migraine.

Berdasarkan hasil evaluasi nyeri sebelum tindakan massage menunjukkan rata-rata responden mengalami nyeri sedang, dan setelah dilakukan intervensi didapatkan penurunan nilai nyeri menjadi nyeri ringan, serta hasil uji statistic menunjukkan nilai signifikan 0.000 yang berarti ada pengaruh Swedish massage terhadap penurunan nilai nyeri migraine pada lansia. Berdasarkan teori yang dikemukakan oleh Goettz (2003) menjelaskan bahwa massage memberikan efek terhadap sirkulasi darah setempat maupun seluruh tubuh. Tindakan massage memberikan efek pada system syaraf parasimpatis yang memungkin terjadinya relaksasi. Kondisi relaksasi memungkinkan sirkulasi darah menjadi lancar dalam pengiriman oksigen dan produk metabolisme yang ke system syaraf pusat (Schroeder, 2018). Gerakan efflurage pada Swedish massage memberikan pengaruh pada peningkatan aliran darah vena yang dapat menurunkan tekanan vena dan meningkatkan sirkulasi arteri. Gerakan kneading memberikan bantuan dalam aliran balik vena, sedangkan tindakan kompresi dapat meningkat sirkulasi pembuluh darah lokal dan tepi. Kondisi inilah yang memungkinkan terjadinya penurunan nyeri kepala atau migraine pada lansia.

\section{KESIMPULAN}

Berdasarkan penelitian tersebut menunjukkan bahwa ada pengaruh swedish massage terhadap penurunan nilai nyeri kepala karena migraine pada lansia, sehingga penting pada lansia untuk bisa mempelajari tindakan Swedish massage yang efektif untuk mengurangi migraine.

\section{UCAPAN TERIMAKASIH (ACKNOWLEDGEMENT)}

1. Kepada segenap jajaran pimpinan STIKES 
Katolik St. Vincentius a Paulo yang telah memberikan kesempatan dan ijin untuk melaksanakan proses penelitian.

2. Pengelola panti werdha St Yosef dan kelompok lansia pelangi Nusantara yang juga telah mefasilitasi proses penelitian.

Kegiatan penelitian ini sepenuhnya dibiayai oleh DRPM Kemenristekdikti 2020.

\section{DAFTAR PUSTAKA}

Boru, U.T., Kocer, A., Sur, H., Tutkan, H. and Atli, H. (2005). Prevalence and Characteristics of Migraine in Women of Reproductive Age in Istanbul, Turkey: A Population Based Survey. Tohoku J. Exp. Med., 206(1), 51-59.

Cady,R.(2007). Pathophysiology of Migraine. In: The Pain Practitioner; 17(1): 6-9

Davis, LE., King M.L.,Schulz JL.(2006). Disoerder of pain and headache. In: Fundametals of Neurologic Disease Demos Medical Publishing,New York, 201-7

Efendi, Ferry dan Makhfudli. (2009). Keperawatan Kesehatan Komunitas: Teori dan Praktik dalam Keperawatan. Jakarta: Salemba Medika

Goadsby, P.J., Lipton, R.B., Ferrari, M.D. (2002). Migraine - Current Understanding and Treatment, $N$ Engl J Med 346:257-270 January 24

Goetz GC. (2003). Headache and Facial Pain.In : Texbook of Clinical Neurology. Second edition.Elsevier Science. USA: 1187-94

Schroeder RA, Brandes J, Buse DC, Calhoun A, Eikermann-Haerter K, Golden K, et al. (2018) Sex and Gender Differences in Migraine-Evaluating Knowledge Gaps. $J$ Womens Health (Larchmt) 